\title{
TROCAS CULTURAIS NO "RIO ATLÂNTICO": ANGOLA NO AUGE DO TRATO DE ESCRAVOS
}

FERREIRA, Roquinaldo Amaral. Cross-Cultural Exchange in the Atlantic World: Angola and Brazil during the Era of the Slave Trade. Cambridge: Cambridge University Press, 2012. 262 p.

$O$ Atlântico como rio: o símile, do historiador Alberto da Costa e Silva, ressalta o quanto o oceano uniu a África e o Brasil, facilitando sua comunicação na época moderna. ${ }^{1}$ Em Cross-Cultural Exchange in the Atlantic World, Roquinaldo Amaral Ferreira, professor da Brown University, EUA, aprofunda o tema. O enfoque é no intercâmbio entre Angola e Brasil, mais especificamente nas trocas culturais efetivadas, na margem angolana do "rio", entre africanos, portugueses e brasileiros durante o período-auge do comércio de escravos (c. 1680-1850).

O livro é a primeira monografia publicada de Ferreira, mas o terceiro trabalho de fôlego dele sobre as ligações entre Angola e o mundo luso-brasileiro no período escravista. $\mathrm{O}$ atual estudo vai na esteira de suas te-

\footnotetext{
Alberto da Costa e Silva, Um rio chamado atlântico: a África no Brasil e o Brasil na África, Rio de Janeiro: Nova Fronteira, 2003.
}

ses de mestrado e doutorado. ${ }^{2}$ Como os trabalhos anteriores, o novo texto impressiona, tanto pela densidade da pesquisa em arquivos variados angolanos, portugueses e brasileiros -, quanto pela inovação metodológica e temática. Faz jus ao padrão de excelência da prestigiosa série da qual faz parte, a "African Studies" (iniciada em 1968) da Editora da Universidade de Cambridge. Com ele, e com suas duas teses inéditas, o brasileiro Ferreira se projeta para o primeiro time internacional de historiadores da África.

Como indica no título da obra, Ferreira dialoga com o conceito de

\footnotetext{
2 Roquinaldo Amaral Ferreira, "Dos sertões ao Atlântico: tráfico ilegal de escravos e comércio lícito em Angola, 1830-1860" (Dissertação de Mestrado em História, Universidade Federal do Rio de Janeiro, 1996); Roquinaldo Amaral Ferreira, "Transforming Atlantic Slaving: Trade, Warfare and Territorial Control in Angola, 1650-1800 (Tese de Doutorado, University of California, Los Angeles, 2003).
} 
“mundo atlântico". Embora ele conheça a fundo a bibliografia sobre o atlântico anglo-americano, onde o conceito se originou, seu ponto de partida é um ensaio de Robin Law e Kristin Mann a respeito de outra região do atlântico luso, aquela que engloba o Recôncavo da Bahia e o golfo de Benim. ${ }^{3}$ Segundo Ferreira (p.10), para Law e Mann

[...] o trato de escravos entre Bahia e a África ocidental era caracterizado por comunidades [atlânticas] transculturais altamente fluidas, cujas origens estavam no papel-chave desempenhado por indivíduos de cultura mista [...] [que eram] predominantemente negociantes (p. 10).

Ferreira encampa a idéia de "comunidade atlântica", porém faz duas observações importantes ao transpor o conceito ao estudo dos elos entre Brasil e Angola.

Primeiro, ele rejeita a noção de Law e Mann de que uma tal "comunidade" não teria se desenvovido nas regiões de Luanda e Benguela porque Portugal efetivamente se impusera lá como potência colonial, ao contrário do que acontecera no Golfo de Benim, onde havia um relativo vácuo de poder político europeu. $\mathrm{Na}$ verdade, pondera Ferreira, o controle de Portugal sobre Angola estava longe de ser absoluto, mesmo no século XVIII e início do XIX; dependia de

Robin Law e Kristin Mann, "West Africa in the Atlantic Community: the Case of the Slave Coast", William and Mary Quarterly, v. 56, n. 2 (1999), 307-31. negociações com chefes africanos e encontrava limites em reinos interioranos militarmente fortes (o de Cassanje, por exemplo). Como resultado,

[...] a costa angolana e algumas partes do interior eram caracterizadas por uma dinâmica cultural e social altamente amalgamada. De um lado, os africanos se apossavam de elementos da cultura européia para reforçar as hierarquias sociais entre eles. De outro, algumas partes do aparelho legal da colônia e do tecido cultural e religioso da "Angola portuguesa" eram baseadas em instituições africanas (p. 12).

A segunda observação de Ferreira é que, no caso de Angola, as trocas transculturais e mesmo as transoceânicas não envolviam, predominantemente, negociantes; grande diversidade de gente participava desses intercâmbios, inclusive escravos e ex-escravos retornados do Brasil, alguns fazendo a viagem de ida e volta mais de uma vez.

Como veremos, no entanto, as duas observações, baseadas na análise empírica desenvolvida no livro, não levam o autor a concordar com uma ideia que vem ganhando força na bibliografia, a de que a Angola sob influência portuguesa era uma "sociedade crioula".

No que tange a questões de método, a perspectiva de Ferreira é a da história social. Ele se afilia explicitamente à micro-história, a estratégia de reduzir a escala de observação visando a reconstituir as relações e 
redes socais ao rés do chão para poder pensar de forma consequente o quadro macro. Inspira-se, em parte, na vertente italiana dessa abordagem, com sua ênfase no "excepcional normal” (a exceção que revela a norma), porém prioriza a micro-história "do ordinário" ou da "vida cotidiana". Propõe, para essa finalidade, uma abordagem "biográfica" que "coloque os africanos e seus descendentes no centro de suas próprias histórias" (p. 5). Para ponderar criticamente o sentido de histórias de vida que são quase sempre fragmentárias, dada a natureza lacunar da documentação, Ferreira procura, à maneira do antropólogo Clifford Geertz,

[...] elaborar descrições densas de indivíduos baseadas em análises detalhadas de uma vasta e eclética variedade de fontes primárias, muitas das quais raramente - ou até nunca - usadas antes por estudiosos da Africa e do mundo atlântico (p. 6).

A referência aqui é à documentação compulsada pelo autor em diversos arquivos em Luanda e Benguela, além dos fundos pesquisados em Lisboa e no Rio de Janeiro. Destacam-se, no rol das fontes, processos judiciais diversos, correspondência da Câmara Municipal de Luanda, inventários post-mortem e testamentos, documentação notarial, ofícios entre governadores, chefes africanos, autoridades de presídios (fortes) no interior e representantes (capitães-mores) junto a reinos afri- canos (o de Cassanje, por exemplo). Em muitas ocasiões, Ferreira consegue fazer uma ligação nominativa de fontes que permite seguir indivíduos entre séries documentais.

O especialista brasileiro pode estranhar o contexto específico, angolano, das histórias que surgem dessa documentação, mas se sentirá em casa ao ver a semelhança tipológica entre boa parte das fontes usadas e aquelas do historiador social na margem de cá do "rio" — um reflexo, evidentemente, da presença do mesmo arcabouço institucional do império luso nos dois lados. Aliás, não há dúvida de que a formação brasileira do autor como também a abordagem biográfica com ligação de fontes, que vem sendo cultivada já faz tempo por historiadores do Brasil (e do Brasil no mundo atlântico), the abriram caminhos. Isso fica claro nas citações em notas, mas teria sido interessante (especialmente para o leitor anglófono, para quem esta edição é destinada) uma reflexão metodológica a respeito do assunto - por exemplo, sobre as afinidades e eventuais diferenças entre a sua abordagem biográfica e as de Regina Xavier, João Reis, o mesmo Reis com Flávio Gomes e Marcus de Carvalho, James Sweet, e outros. ${ }^{4}$

\footnotetext{
4 Regina Célia Lima Xavier, A conquista da liberdade: libertos em Campinas na segunda metade do século XIX, Campinas: Centro de Memória da Unicamp, 1996; João José Reis, Domingos Sodré, um sacerdote africano: escravidão, liberdade e candomblé na Bahia do século XIX, São Paulo: Companhia das Letras, 2008; João José Reis, Flávio dos
} 
I

Cross-Cultural Exchange se divide em seis capítulos. $\mathrm{O}$ autor explicita que os três primeiros têm uma certa unidade temática: enfocam questões em torno do crescimento do comércio de escravos dentro da área de influência portuguesa e suas consequências sociais e jurídicas. Da mesma forma, os últimos três capítulos tratam de aspectos iterligados de história sociocultural, religiosa e política, e o enfoque ainda recai sobre a área "portuguesa" - principalmente Luanda e seu interior, embora também inclua Benguela e seu sertão.

O primeiro capítulo aborda o crescimento da atividade de sertanejos e pumbeiros, pequenos negociantes no trato de escravos na hinterlândia "portuguesa" (ou seja, entre o mar e os reinos ambundo, especialmente Matamba e Cassanje, que bloqueavam o acesso direto desses mercadores ao comércio de escravos no interior profundo). O contexto é o do grande aumento da demanda brasileira por cativos (entre final do século XVII e primeira metade do XIX). A narrativa aqui se estrutura em torno da carreira em Angola de um homem branco e ex-proprietário de navio

Santos Gomes e Marcus de Carvalho, O alufá Rufino: tráfico, escravidão e liberdade no Atlântico negro (c. 1822-c. 1853), São Paulo: Companhia das Letras, 2010; James Sweet, Domingos Álvares, African Healing, and the Intellectual History of the Atlantic World, Chapel Hill: University of North Carolina Press, 2010. negreiro, proveniente da Bahia. Em meados do XVIII, esse personagem se torna negociante sertanejo, em seguida, representante do governador em Luanda junto ao reino de Holo (reino ambundo), com a missão - frustrada — de contornar o monopólio de Matamba e Cassanje sobre o trato sertão adentro, e, finalmente, capitão-mor de Caconda (presídio no interior de Benguela), posto que lhe facilita engajamento intenso no comércio de cativos. Ao recontar a história desse homem, Ferreira apresenta - seguindo uma estratégia narrativa usada na maioria dos capítulos do livro - fragmentos de biografias paralelas de outros sujeitos (nesse caso, também mercadores), para traçar um quadro denso e ao mesmo tempo amplo da "geopolítica do comércio na hinterlândia de Luanda" (pp. 16-7). Ele esclarece, por exemplo, as tensões entre a comunidade de negociantes em Luanda ("moradores") e os mercadores "estrangeiros" (brasileiros). E demonstra o grande crescimento do tráfico na região dominada por Portugal.

O segundo capítulo examina as consequências sociais desse aumento no comércio itinerante dos sertanejos/pumbeiros,

[...] particularmente com respeito aos vassalos africanos, indivíduos que viviam em territórios controlados por chefes autóctones aliados a Portugal (p. 52).

A narrativa, dessa vez, recons- 
trói diversas histórias miúdas, para traçar um quadro detalhado das relações entre negociantes em Luanda e Benguela e sertanejos, e entre eles e chefes africanos no interior. Examina, também, os vários tipos de mercadores envolvidos no comércio sertanejo. Finalmente, demonstra os esforços de alguns governadores (preocupados em manter as alianças politicas estabelecidas) para proteger vassalos livres de uma "escravização injusta". Vale a pena citar por extenso algumas das conclusões de Ferreira a respeito das origens dos africanos comercializados e das maneiras pelas quais foram escravizados, pois, como veremos mais adiante, são contribuições incisivas ao debate atual sobre a configuração do comércio de escravos dentro da África Central:

Os estudiosos têm presumido que a chamada fronteira de escravização [slaving frontier: termo cunhado pelo historiador Joseph Miller] de Angola movia-se continuamente para o leste ao longo do século XVIII, e que a maioria dos africanos escravizados e embarcados para a América veio de regiões fora da influência portuguesa. Este capítulo demonstrou que as redes oportunistas criadas por sertanejos e pumbeiros também afetaram profundamente vassalos africanos que viviam em regiões sob influência portuguesa (p. 87).

O aumento da demanda brasileira por escravos, junto com o controle exercido pelos reinos de Matamba e, especialmente, Cassanje sobre o comércio vindo da "fronteira de escravização" no interior profundo,

[...] tornaram os vassalos africanos [na região portuguesa] vulneráveis à escravização. Este processo também foi impulsionado pela demanda por bens nos sertões [tanto na região portuguesa quanto na fronteira de escravização], que moldaram a dinâmica social e legal de maneira a permitir que negociantes litorâneos, autoridades internas, e principalmente mercadores itinerantes, pudessem mover demandas judiciais contra sobas [chefes locais] e pessoas comuns. Demandas que resultaram em escravização de legalidade duvidosa — através de dívidas, acusações de feitiçaria e raptos endêmicos. Este ciclo vicioso transformou a instituição de penhora de gente numa máquina de produzir escravos (p. 87).

No terceiro capítulo, Ferreira enfoca as iniciativas de africanos arrebatados por esse vendaval crescente de escravizaçao. E dá continuidade à história da preocupação do governo português com o cativeiro ilegal, perpetrado frequentemente por seus próprios agentes e visto como ameaça ao domínio da Coroa. Novamente, a narrativa se estrutura em torno de uma biografia: a de uma mulher liberta, cujo filho, nascido livre, é levado cativo para o Brasil, mas consegue acionar a Justiça lusa para retornar, e que, em momento posterior, é ameaçada, ela mesma, de escravização. Adensando a história com outras experiências semelhan- 
tes e contrastantes, o autor demonstra a "fluidez" da fronteira entre escravidão e liberdade vivenciada por muitos cativos "ladinos" (nascidos em Luanda), que com certa frequência conseguiam mobilizar pessoas e instituições poderosas dentro de suas redes sociais (por exemplo: padres e a Irmandade do Rosário), para se proteger contra a ameaça do cativeiro.

O enfoque principal do capítulo, no entanto, é o "Tribunal dos mucanos" (mucano significa "litígio" em quimbundo, a língua dos ambundos, da região de Luanda e seu interior). Trata-se de uma encruzilhada institucional e documental - entre a escravização ilegal e as tentativas dos africanos e da Coroa portuguesa de combater esse abuso. Originalmente uma instância jurídica africana de âmbito local, subordinada ao soba, a instituição se verticalizou com o tempo; os tribunais locais, nas regiões de maior influência portuguesa, acabaram sendo subordinados aos capitães-mores. Por causa dos abusos destes últimos, que amiúde lucravam com a condenação e venda de africanos que reclamavam sua liberdade, criaram-se tribunais de última instância em Luanda e Benguela, subordinados, em alguns momentos, aos governadores e, em outros, a autoridades diversas, com a esperança de que uns combatessem a corrupção de outros. No contexto de uma enorme expansão do comércio de cativos, as "ações de liberdade" levadas a esses tribunais também aumentaram em número - devido, em parte, segundo o autor, à própria iniciativa dos africanos afetados e viraram o principal tipo de litígio julgado. Este capítulo, junto com o anterior, de certa forma dá continuidade, no século XVIII, à história da conturbada relação entre a Coroa e seus funcionários em Angola no século XVI e XVII, contada por Linda Heywood e John K. Thornton. ${ }^{5}$ Acima de tudo, é uma impressionante história social de lutas africanas pela liberdade, travadas numa instituiçao em que práticas jurídicas autóctones e portuguesas se imbricavam.

\section{II}

Parece-me oportuno me estender um pouco sobre a importância dos três primeiros capítulos para o conhecimento dos fluxos do comércio centro-africano de escravos, dentro do continente e em direção ao Brasil. Ferreira não se alonga com respeito ao debate historiográfico sobre o assunto, além de resumir e relativizar a contribuição de Joseph Miller. Possivelmente, ele presume que os especialistas em história centro-africana do período já estão por dentro do assunto. Para outros africanistas, no entanto, e especialmente para historiadores da diáspora, para os quais o tema é de grande interesse mas a bibliografia especifica não tão conhecida, é útil adensar a discussão. E mesmo para a história social da região enfocada por Ferrei-

\footnotetext{
5 Linda Heywood e John K. Thornton, Central Africans, Atlantic Creoles and the Foundation of the Americas, 1585-1660, Nova York: Cambridge University Press, 2008.
} 
ra, um balanço do "estado da arte", no que diz respeito às origens das pessoas traficadas, pode jogar nova luz sobre as trocas transculturais, especialmente aquelas entre africanos.

Em Way of Death, Miller compara a "fronteira de escravização" na África Central ocidental a uma onda, que vai avançando continente adentro, até chegar praticamente aos grandes lagos no período 18301850. Nessa fronteira, a escravização acontece principalmente como resultado de guerras provocadas pela demanda por cativos na América e também (como consequência) na "Zona Atlântica" da África. Esta última é uma região "móvel”, constituída pela área deixada atrás pelo avanço da onda da fronteira de escravização. Nela, se restabelece a "paz" em torno de sociedades caracterizadas agora como "escravistas", ou seja, com percentagem significativa de sua população reduzida ao cativeiro. Entre elas estão os reinos de Matamba e Cassanje, cujo poder de manter o monopólio sobre os cativos vindo do interior profundo provém, em última análise, de sua "riqueza" em dependentes escravizados. ${ }^{6}$

No modelo de Miller, outros reis e sobas da Zona Atlântica, procurando aumentar o número de seus dependentes, compram escravos principalmente mulheres — oriundos da fronteira, endividando-se

\footnotetext{
6 Joseph Miller, Way of Death: Merchant Capitalism and the Angolan Slave Trade, 1730-1830, Madison: University of Wisconsin Press, 1988.
}

para isso com os fornecedores de mercadorias em demanda no interior. São então forçados a vender muitos dos dependentes - cativos comprados ou seus filhos — para saldar dívidas; eventualmente, também penhoram dependentes livres que depois não conseguem resgatar e acabam escravizados. Miller argumenta, enfim, que tanto a fronteira escravista quanto a Zona Atlântica fornecem cativos (sobretudo homens) para as Américas. Entretanto, salvo engano, ele não se arrisca a calcular o tamanho relativo dos dois grupos de procedência. Na verdade, pela ênfase dada na narrativa à fronteira de escravização, o leitor fica com a impressão de que essa área é a principal fornecedora de cativos para o comércio oceânico. De fato, em trabalhos posteriores, Miller volta ao tema, para frisar que a proporção vinda da fronteira, junto com a variedade dos povos atingidos, aumenta consideravelmente no final do século XVIII e permanece nesse patamar, ou até cresce mais ainda, até o final do trato. ${ }^{7}$

Fica evidente, portanto, que Ferreira comprova, com mais densidade

\footnotetext{
7 Joseph C. Miller, "Central Africa During the Era of the Slave Trade, 1490s-1850s", in Linda M. Heywood (org.), Central Africans and Cultural Transformations in the American Diaspora (Cambridge: Cambridge University Press, 2002), pp. 21-69, esp. pp. 54-63. Ver também Joseph C. Miller, "Restauração, reinvenção e recordação: recuperando identidades sobre a escravização na África e face à escravidão no Brasil", Revista de História, n. 164 (2011), pp. 17-64.
} 
empírica, a tese de Miller a respeito do ciclo de endividamento de chefes na Zona Atlântica de influência portuguesa, especialmente na hinterlândia de Luanda, e, portanto, a crescente dinâmica do trato de escravos dessa região. Isso o leva a relativizar a outra parte da tese de Miller a respeito do predomínio, no trato atlântico, de cativos vindos do interior profundo, embora não ao ponto de rejeitá-lo por completo, pois seus dados não permitem uma quantificação precisa das duas correntes do tráfico. Ora, Thornton e Heywood têm contribuições semelhantes com relação à dinâmica do comércio de escravos na Zona Atlântica que vai da embocadura do Rio Zaire para pontos na costa mais para cima, entre o início do século XVIII e meados do XIX. Além disso, Thornton calcula (utilizando dados dos anos 1780 ) em quase $50 \%$ a participação do antigo reino do Congo (ou seja, em mais de $50 \%$ a proporção proveniente da região cultural congo, que ia além das fronteiras do reino). ${ }^{8}$

Recentemente, também Mariana Candido chegou a conclusões semelhantes, de fato mais contundentes, com relação aos cativos saídos de Benguela no mesmo período. Pra-

\footnotetext{
8 John Thornton, "As guerras civis no Congo e o tráfico de escravos: a história e a demografia de 1718 a 1844 revisitadas", Estudos Afro-Asiáticos, n. 32 (1997), pp. 55-74, esp. 66-7; Linda Heywood, "Slavery and its Transformation in the Kingdom of Kongo: 1491-1800", The Journal of African History, v. 50, n. 1 (2009), pp. 1-22.
}

ticamente a totalidade deles se teria originado no planalto de Benguela (dos grupos posteriormente chamados de ovimbundos), ou seja, da região sob influência portuguesa. ${ }^{9}$ Thornton e Candido colocam em dúvida a idéia de Miller de que o "recrutamento" de escravos na Zona Atlântica para o comércio americano resultou quase inteiramente de processos sociais "pacíficos". Tanto no antigo reino do Congo, quanto em Benguela, um grande número de pessoas foi escravizado por meio de guerras ou razias. Ferreira conhece esses trabalhos (os cita nas notas), mas não os discute em seu texto. Se tivesse integrado seus resultados aos dos outros estudiosos, poderia ter levantado dúvidas mais consistentes sobre o modelo de procedências dos escravos de Miller.

A pesquisa continua, em todo caso, e agora há um trabalho sobre africanos chegados à margem brasileira do Atlântico que reforça, e muito, o conjunto de pesquisas mencionado. Em dissertação de mestrado, Marcos Abreu Leitão de Almeida estudou os etnônimos fornecidos pelos escravos em navios negreiros interceptados e trazidos ao Rio de Janeiro nos anos 1834-1839, para serem julgados pela comissão mista Brasil-Inglaterra. Plotando essas patrias chicas no mapa, Almeida pôde

\footnotetext{
Mariana Pinho Candido, "Enslaving Frontiers: Slaving, Trade and Identity in Benguela, 1780-1850" (Tese de Doutorado em História, York University, 2006).
} 
demonstrar que a grande maioria dessas pessoas veio da Zona Atlântica mais antiga, que abarcava a região de influência portuguesa em Angola e o reino do Congo, como também as terras de alguns povos vizinhos ao leste. ${ }^{10}$ Isso não quer dizer que o interior profundo não tenha destinado um grande número de escravos para as sociedades da Zona Atlântica ou, pelo menos, para a região dos congos e ambundos. $\mathrm{O}$ que indica é que a grande maioria dos egressos dessas sociedades para a América havia sido parcialmente socializada na área litorânea (o caso de migrantes "em trânsito", alguns por bastante tempo) ou completamente socializada nela (o caso dos filhos de escravas provenientes da fronteira de escravização, ou dos filhos de vassalos e escravos nascidos naquelas sociedades). Enfim, a tese de Miller sobre a pulverização das origens das pessoas da África Central ocidental (em suas palavras, a predominância de gente banto "genérica") no Brasil a partir do final do século XVIII, provavelmente não é mais sustentável. Tudo indica que a senzala do Brasil sudeste - e talvez a de Luanda e Benguela - foi habitada sobretudo por gente linguística e culturalmente muito próxima (congo, ambundo, ovimbundo e vizinhos) - mesmo que a cultura da

\footnotetext{
10 Marcos Abreu Leitão de Almeida, "Ladinos e boçais: o regime de línguas do contrabando de africanos (1831-c. 1850)" (Dissertação de Mestrado em História, Universidade Estadual de Campinas, 2012).
}

maioria desses grupos tivesse sofrido transculturações significativas no período, pelo forte afluxo de gente interiorana. ${ }^{11}$

\section{III}

Voltemos ao livro em revista. O quarto capítulo passeia por Luanda com visitas a Benguela. Flagra o dia a dia de cativos e senhores, dando destaque à "paisagem linguística", às "tabernas", e à "segurança pública e controle social". Incluída neste último tema é a prática de deportar escravos e libertos malcomportados para o Brasil - um terror para os dois grupos, pois, segundo o governador em 1800 ,

[os africanos de] algumas nações [...] estão convencidos de que nós os compramos para fritá-los e extrair óleo de seus corpos [p. 158].

O quadro desenhado é semelhante ao do Rio de Janeiro na primeira metade do século XIX. Há escravos por toda parte, em todo o tipo de serviço e dominando certos ofícios, como o de barbeiro. Eles desfrutam de grande mobilidade, os homens em bares às turras com gente livre, as mulheres muitas vezes agindo como quitandeiras ou empregadas

\footnotetext{
11 Ver também: Robert W. Slenes, “'Eu venho de muito longe, eu venho cavando': jongueiros cumba na senzala centro-africana", in Silvia Hunold Lara e Gustavo Pacheco (orgs.), Memória do jongo: as gravações históricas de Stanley J. Stein. Vassouras, 1949 (Rio de Janeiro/Campinas: Folha Seca/CECULT, 2007), pp. 109-56, esp. pp. $115-21$
} 
como prostitutas. Há um número substancial de libertos à vista, com proporcionalmente mais mestiços entre eles do que entre os escravos. Há senhoras da elite que não sabem escrever; e assim por diante.

Mas existem, também, contrastes grandes com o Rio de Jneiro. Por exemplo, há muitos africanos ladinos empregados como caixeiros nas lojas de negociantes e também no interior como amanuenses e secretários dos sobas. Há muitos tripulantes (escravizados) de navios negreiros, mais visíveis em Luanda (cidade menor) do que no Rio de Janeiro, forçados a fazer a carreira entre Angola e Brasil, frequentemente como "línguas" (tradutores). Encontram-se senhoras de elite que falam português (muitas com sotaque brasileiro) quando em família, mas usam quimbundo - a língua mais falada em Luanda - para lidar com as escravas. Há autoridades preocupadas em "importar" mulatos do Brasil para aumentar o número de falantes de português. Como nos capítulos anteriores, Ferreira conta uma história que serve como princípio organizador do texto: a de um escravo africano, recém-liberto em Angola, preso por suspeita de furto. O homem consegue driblar a polícia por um tempo, alegando que retornara do Brasil, para onde remetia (ao irmão, aínda escravizado lá) pequenos artigos para venda; era daí, dizia, que provinha seu dinheiro. Tudo se revela uma farsa; mas os vários casos, contados por Ferreira, de escravos que voltaram, sim, da- quele outro lado do "rio" indicam por que a história podia parecer verossímil.

A viga mestra do capítulo seguinte é a história de uma africana acusada em Luanda, em 1726, de ser ganga ("feitiçeira", para a Igreja Católica; "sacerdotisa, curandeira, intermediária entre o mundo dos mortos e o dos vivos", para o povo ambundo). Ferreira explora a fundo a fonte principal sobre o caso, um processo da Inquisição, mas vai muito além dela, reconstruindo, com a ajuda de outra documentação, as biografias da mulher e de dois de seus amantes. Um deles é um padre católico mestiço, ex-contrabandista de escravos em Benguela, de grande influência política em Luanda; o outro é um brasileiro branco, degregado à Angola pelo crime de assassinato, que, posteriormente, chega a ser o representante do governador de Angola em Cassanje. Lá, ele exerce o papel de ganga; preside rituais de juramento para determinar a culpabilidade de réus em contendas jurídicas (ficando com uma parte dos escravos e outros bens dos condenados, como pagamento).

Contextualizando essa história mirabolante, Ferreira examina outros casos de gangas em Luanda e Benguela, para construir um perfil delas (e deles), seu papel na comunidade africana, as ocasiões em que eram chamadas a agir (por africanos e europeus), seus rituais e cosmologia. Da mesma forma, discorre sobre as características e carreiras do conjunto de degregados portugueses e 
brasileiros nas regiões angolanas de influência portuguesa. O resultado, matéria excelente para um roteiro de filme, é também "bom para o historiador pensar".

Diz o autor (p.189):

Em Luanda e Benguela, esferas culturais imbricadas combinavam elementos das culturas africana e portuguesa, criando dessa maneira oportunidades para que gente estrangeira se integrasse em comunidades fluidas e transculturais (grifos meus).

Trocando em miúdos (pp. 201202), criou-se

[...] um ambiente sociocultural [..] [que] permitia aos indivíduos evitarem compromissos permanentes com uma única identidade. Ao mesmo tempo, a religião e a cultura serviam como forças unificadoras que atravessavam os diversos segmentos dessas comunidades, formando um meio cultural vibrante [...e integrador].

O sexto capítulo, trata das ligações mercantis, sociais e políticas entre Benguela e o Rio de Janeiro. $\mathrm{O}$ enfoque biográfico recai num homem preto, nascido no Rio, possivelmente de origem escrava. Degredado para Benguela em 1800, fez carreira como oficial do Batalhão dos Henriques (de soldados pretos) da cidade, caixeiro de um mercador importante, funcionário público em diversos setores da administração, finalmente grande negociante com o planalto de Bengue- la (para onde remetia caravanas de bens importados, principalmente do Brasil) e traficante de escravos para o Rio de Janeiro. O biografado era dono (com um sócio português de Benguela) de dois navios negreiros e tinha propriedades agrícolas que abasteciam a população da cidade e escravos em trânsito para o Rio de Janeiro. Na época, sua firma era das poucas que não contavam com aporte de capitalistas residentes no Rio, donos do comércio entre Benguela e Brasil a partir da segunda metade do século XVIII. Ao contar a história desse homem, Ferreira tece outras biografias com pontos ou trajetórias semelhantes, o que lhe permite esboçar uma história social dos Henriques em Benguela, das possibilidades de enriquecimento em diversos setores da administraçao local e das redes criadas pelas "intensas trocas sociais, religiosas e familiares" (p. 221) de grandes e pequenos negociantes com gente residente no Rio de Janeiro.

Além disso, Ferreira elucida, neste capítulo, as tensões políticas em Benguela na época da independência do Brasil. O biografado foi preso em 1824, junto com outros quatro negociantes abastados, sob suspeita de planejar a adesão de Benguela à causa brasilera, a morte aos "pés de chumbo" (os portugueses) e a transferênca do poder político aos pretos, à semelhança (alegava-se) do que acontecera no Haiti. Pouco tempo depois, no entanto, as acusações foram retiradas, e os acusados acabaram reintegrados à sociedade, 
onde continuavam a prosperar do comércio com a outra margem do Atlântico. O caso, contudo, permite a Ferreira construir um relato detalhado da rivalidade entre as juntas de Benguela e Luanda, criadas na esteira da revolução liberal de 1820 em Portugal, num contexto em que a união política do Sul de Angola com um Brasil independente não parecia fora de cogitação, dada a integração já existente etre as duas regiões. Conclui o autor (p. 241):

[...] a presumida revolta em Benguela nos diz mais sobre o medo português com relação ao fluxo dos eventos no Brasil e à circulação de ideias no Atlâtico, do que a respeito da natureza real dos conflitos políticos em Benguela.

IV

Ferreira termina o livro com um epílogo curto em que procura delinear a relevância de sua pesquisa dentro do contexto historiográfico atual.

Ressalta, em primeiro lugar, que, apesar dos avanços inegáveis na construção de narrativas demarcadas "mais pela natureza integrada de encontros transnacionais do que por fronteiras nacionais" (p. 242), a história atlântica ainda se faz predominantemente a partir de uma perspectiva eurocêntrica. Não que os pesquisadores não apreciem a necessidade de reconhecer o protagonismo local; é que a investigação micro-histórica tem avançado menos do que o conhecimento de fluxos e estruturas no nível macro.
Ferreira endereça a crítica não apenas à historiografia sobre o espaço atlântico anglófono, mas àquela sobre o mundo luso-afro-brasileiro. Para ele, o método usado em seu livro, uma "narrativa densa" a partir das "circunstâcias pessoais e trajetórias de indivíduos" (p. 245), é aquele que permite captar a diversidade das experiências e das razões das pessoas em seu cotidiano, devolvendo-lhes o lugar no palco da história.

Em segundo lugar, Ferreira intervém no debate entre "africanistas" (que insistem na continuidade de matrizes africanas em comunidades afrodescendentes na América) e "crioulistas" (que enfatizam a criação de culturas novas em situações de contato colonial, seja com predominância de elementos europeus, seja com maior peso de características africanas), achando as duas abordagens inadequadas. Ele rechaça especialmente a noção de "Atlantic creoles", criada por Ira Berlin e retrabalhada por Thornton e Heywood, ${ }^{12}$ entre outros, para se referir à gente culturalmente crioulizada do lado africano do Atlântico. Tal ideia, segundo ele, "implica [sic: implica um movimento de aproximação a?] crenças religiosas estáticas baseadas no cristianismo" (p. 248). Todos esses conceitos

\footnotetext{
12 Ira Berlin, "From Creole to African: Atlantic Creoles and the Origins of African-American Society in Mainland North America", William and Mary Quarterly, v. 53, n. 2 (1999), pp. 251-88; Heywood e Thornton, Central Africans.
} 
[...] nem de longe descrevem adequadamente os tecidos sociais, culturais e legais pluralistas das comunidades da costa de Angola e de sua região interiorana (p. 148).

Nessas sociedades,

[...] diferentes esferas culturais, religiosas e legais existiam lado a lado, o que permitia aos indivíduos se aproveitarem de recursos relevantes a circunstâncias momentâneas. [...]. Como não é de se surprender, as identidades sociais e culturais estavam em constante construção, com notável ambigüidade e ambivalência no que diz respeito à raça e ao status social (p. 248).

As considerações de Ferreira no epílogo são instigantes, mas não fazem jus à riqueza de seu livro, que demanda uma conclusão teórica e historiográfica mais elaborada. No que diz respeito à primeira questão abordada - a relativa falta de estudos de micro-história biográfica - já salientei que fica a desejar uma discussão de maior fôlego sobre outras contribuições desse tipo, especialmente para o espaço brasileiro no período escravista. No que diz respeito à segunda questão — a crítica às escolas "africanista" e "crioulista" —, seus comentários são telegráficos demais para leitores não especialistas. Além disso, duvido que os defensores do conceito de "Atlantic Creoles" aceitassem que ele implique uma aproximação à idéia de "crenças religiosas estáticas baseadas no cristianismo", embora eu também considere o conceito de "crioulização" uma ferramenta teórica pouco afiada. A caracterização da sociedade angolana como culturalmente "pluralista", oferecendo "recursos" para indivíduos das mais diversas procedências e resultando em identidades "em constante construção", é certamente convincente, dado o lastro de pesquisa que a sustenta. "Comunidade pluralista" (ou "contextos pluralistas", p. 245), no entanto, lembra os termos "sociedade plural" e "pluralismo cultural" frequentemente usados meio século atrás para caracterizar as sociedades coloniais do Oriente e do Caribe, porém com sentido bem diferente. ${ }^{13}$ (Referiam-se a situações em que dois ou mais grupos étnicos, vivendo lado a lado, mantinham instituições sociais e culturais "paralelas", que raramente se cruzavam.) Pergunto-me, portanto, se a noção proposta por Mary Louise Pratt de "transculturação" (palavra, aliás, frequentemente usada por Ferreira) na "zona de contato [colonial]" não seria preferível. Afinal, o significado que Pratt dá a esses termos - a apropriação seletiva de aspectos das culturas dos outros, realizada na política do dia a dia dos indivíduos que interagem em contextos coloniais -

\footnotetext{
13 M. G. Smith, The Plural Society in the British West Indies, Berkeley: University of California Press, 1965. Ver esp. p. vii e 14. Segundo Smith, o termo "plural society" foi cunhado por F. S. Furnivall, estudioso das sociedades coloniais do Sudeste da Ásia.
} 
parece ser bem parecido com a ideia de "comunidade/contexto pluralista" de Ferreira. ${ }^{14} \mathrm{Em}$ todo o caso, seria interessante uma discussão mais aprofundada do conteúdo do termo finalmente escolhido, com exemplos pertinentes tirados dos capítulos anteriores. Também viria ao caso uma ponderação dos estudos recentes e já bastante numerosos sobre as trocas culturais no Brasil escravista. Pois se "Brasil e Angola [...] [eram] um contínuo sociocultural conectado por um oceano" (p. 245), como Ferreira insiste, a nova bibliografia brasileira sobre a interação entre africanos e outros na outra margem do "rio" é essencial para pensar a história social da África "portuguesa".

Essas críticas, no entanto, são de pouca monta; ou melhor, são apenas indagações provocadas pelas sucessivas análises magistrais realizadas por Ferreira, a partir de uma pesquisa empírica extraordinária. Não há dúvida: este livro é um marco nos estudos sobre a história social do mundo sul-atlântico.

Robert Slenes rwslenes@hotmail.com Universidade Estadual de Campinas

${ }_{14}$ Mary Louise Pratt, Imperial Eyes: Travel Writing and Transculturation, Nova York: Routledge, 2008. 